\title{
Ectopic pregnancy: Are fair-colored women at increased risk?
}

Baafuor K. Opoku' ${ }^{1,3^{*}}$, Samuel Blay Nguah² and Wisdom Azanu ${ }^{3}$

*Correspondence: baafuoropoku@yahoo.com

'Department of Obstetrics \& Gynecology, Kwame Nkrumah University of Science \& Technology, Kumasi, Ghana.

2Department of Child Health, Komfo Anokye Teaching Hospital, Kumasi, Ghana.

${ }^{3}$ Department of Obstetrics \& Gynecology, Komfo Anokye Teaching Hospital, Kumasi, Ghana.

\begin{abstract}
Ectopic pregnancies complicate $1-2 \%$ of pregnancies and are potentially fatal as rupture causes severe intra-peritoneal haemorrhage. Both major and minor risk factors have been known for several years. These include damage to the fallopian tubes following previous pelvic infections and tubal surgery. Being fair colored in black women has been suspected to be a risk factor in Ghana for several years despite this not being found in any literature search. A matched case controlled study conducted in Ghana to ascertain this found a highly significant association between ectopic pregnancy and fair skin complexion ( $p<0.001$ at $95 \%$ confidence intervals) irrespective of whether the fairness is natural or artificially induced with skin bleaching creams and soaps. The study found no association between ectopic pregnancy and previous pelvic surgery ( $\mathrm{p}=0.389)$, neither was there any association with lifetime sexual partners $(\mathrm{p}=0.383)$, previous pelvic infections $(\mathrm{p}=0.389)$ or previous termination of pregnancy (p-value 0.485).
\end{abstract}

Keywords: Ectopic pregnancy, fair skin color, black women, pelvic infections

\section{Introduction}

Ectopic pregnancies (EP) implant outside the endometrial cavity. They complicate $1.5-2.0 \%$ of pregnancies and are potentially fatal [1]. It commonly occurs in the fallopian tube and other sites such as the cervix, the ovary and the abdominal cavity. When it ruptures it causes severe intra-peritoneal haemorrhage. Patients with ruptured EP present with signs of shock, including hypotension, tachycardia and rebound tenderness. Those who present before rupture have nonspecific manifestations that are similar to what pertain with a viable intrauterine pregnancy or with abortion/miscarriage. These symptoms and signs include first trimester bleeding (which is typically intermittent, light, and either bright or dark red and which rarely exceeds the normal menstrual flow), crampy lower abdominal or pelvic pain (which is unilateral or diffuse and ranges from mild to debilitating), or both.

Major risk factors for EP include damage to the fallopian tubes from previous pelvic inflammatory disease, tubal surgery and a previous EP $[2,3]$. Minor risk factors include a history of cigarette smoking, age over 35 years and many lifetime sexual partners [2]. There is no clear association between EP and the use of oral contraceptives, previous elective pregnancy termination, uncomplicated miscarriage or caesarean section $[2,3]$. Pregnancy with an intrauterine device in place or after a tubal ligation is rare, but an estimated 25 to $50 \%$ of such pregnancies are ectopic. Women who are subfertile are also at increased risk for EP because altered tubal integrity (or function) contributes to both conditions [4]. In addition, the use of assisted reproductive techniques, especially in vitro fertilization, increases the risk of EP, even among women who do not have damaged fallopian tubes. However, about half of all women diagnosed as EP do not have any of these known risk factors [3,5].

In Ghana the incidence of EP is between 29-32/1000 deliveries $[6,7]$. Over the past several years, observations have been that ectopic pregnancies are seen more frequently in women who are light-coloured or have fair skins in Ghana. However, a search in the literature identifies no such risk. This study was done to scientifically look at this presumed risk factor.

\section{Hypothesis statement}

In a matched case-control study, women presenting to the Obstetrics and Gynecology department of Komfo Anokye Teaching Hospital (KATH) over 12 consecutive months with EP, confirmed after surgery, are more likely to be have fair skins compared to those who have intrauterine pregnancies (IUP).

\section{Null hypothesis}

There is no association between being diagnosed after surgery as having EP and the fairness of the skin in women presenting to KATH over 12 consecutive months.

\section{Objective}

The principal objective was to determine if women presenting to KATH with EP were more likely to be fair in skin complexion compared to those having intrauterine pregnancies.

\section{Methodology}

This was a matched case-control study of women presenting to the Obstetrics and Gynaecology department of KATH with ectopic pregnancy or intrauterine pregnancy between September 2011 and August 2012. All women presenting to the specialist consulting room or admitted to the department's wards of KATH were eligible for the study. 


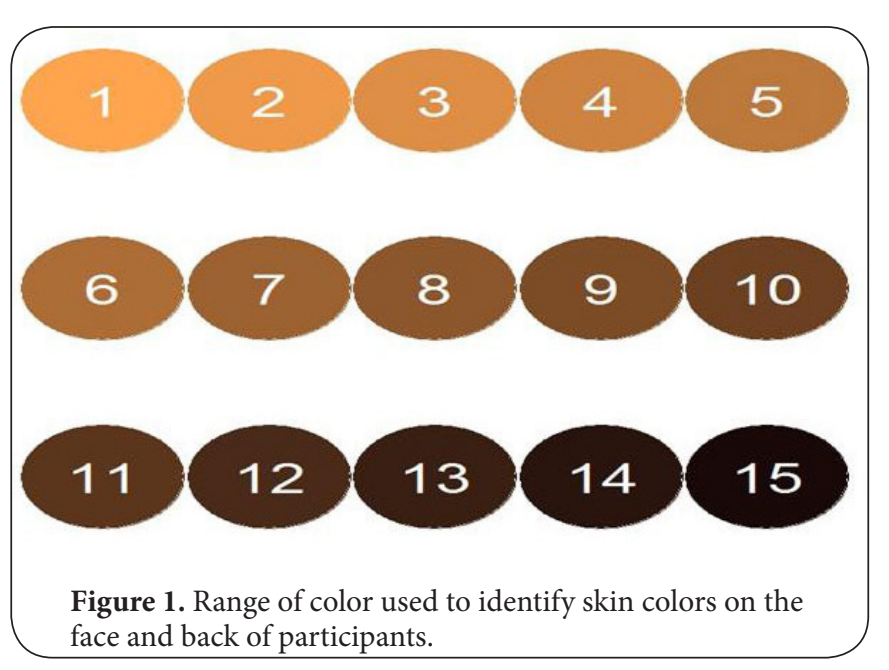

\section{Inclusion criteria}

All patients presenting to the specialist consulting room or admitted to any of the gynaecologic wards:

a. For cases, post-surgery confirmed diagnosis of ectopic pregnancy.

b. For controls, ultrasound confirmed IUP and absence of an EP.

\section{Exclusion criteria}

\section{Lack of consent}

Patients who had laparotomies for ruptured ectopic pregnancy the previous day were administered structured questionnaire after obtaining consent. Data sought included the demographics, social history, past obstetric and gynaecologic history, clinical presentation, intraoperative findings and clinical outcome. A color code (Figure 1) constituting 15 different colors reflecting a range of fairness in black skin colors were used to compare the backs and faces of the patients. This is because the back and face are the parts of the body least and most likely to be altered by direct sunshine and application of bleaching creams/ lotions respectively. The color code closest to the particular body parts was recorded on the data collection form. This determination was done by two trained persons independently. Where there was a discrepancy between the two, a third person was asked to determine which color code among the two previously chosen best fitted the patient's complexion. The color chosen by the third person was then considered the valid skin color.

Two controls were chosen for each case. These were patients from the specialist outpatient clinic or those on admission on the wards with IUP for any other different reason (s). To avoid choosing controls with possible skin pigmentation due to pregnancy, controls were matched for gestational age to be within \pm 2 weeks of the case it is matching. They were administered the same questionnaire, leaving out the section specific to ectopic pregnancy such as the intra-operative findings.

\section{Data collection and analysis}

Data were recorded on a pre-designed case report form that reflected all variables to be collected. The records were doubly entered into electronic case report forms designed using Microsoft ${ }^{\circ}$ Access 2007 software. The data were compared and cleaned on a weekly basis to eliminate inconsistencies. Cleaned data were exported to Stata/SE 11.2 for analysis. A conditional logistic regression model using single predictors for each of the possible associated factors was fitted to determine the odds ratio, 95\% confidence interval and $p$-values. Continuous variables were standardized before model was fitted. P-values less than 0.05 were considered statistically significant.

Ethical approval was obtained from the joint Committee on Human Research, Publications and Ethics (CHPRE) of the Kwame Nkrumah University of Science \& Technology and Komfo Anokye Teaching Hospital.

\section{Results}

A total of 3,961 admissions were made to the gynaecologic wards of the hospital in the period under study. Of these, 418 were ectopic pregnancies, giving a prevalence of $10.6 \%$ of admissions. In all 330 participants were included in the study, 110 cases and 220 controls. Their basic demographics are presented in (Table 1). Their ages ranged from 16-48, with a mean of 27.0 years. Most of the study participants were in employment (43.3\%); very few (5.8\%) had no formal education, and majority had lifetime sex partners of 2-3 (Table 2).

\section{Discussion}

Ectopic pregnancies are serious complications of pregnancy, especially when they are diagnosed after rupture. Although the incidence of ectopic pregnancy may have been falling globally over the past decades [8], it is still a problem in Ghana, especially when ectopic pregnancies are mainly diagnosed after they have ruptured [6]. The incidence of ectopic pregnancy in this study is 33 per 1000 deliveries or 1 in 30 deliveries. This compares well with a study done in Korle-Bu Teaching Hospital in Accra [6].

Over the past several years the suspicion that ectopic pregnancy is found in higher frequencies among women with fairer skin complexions in Ghana has been high. It is an undeniable fact that a lot of men see beauty in fair skin complexion in the country. Fair skinned women are therefore more attractive to men for sexual purposes. They are thus more prone to getting reproductive tract infections, pelvic inflammatory disease and the attendant tubal damage. If this reasoning is correct, then ectopic pregnancies should be seen more often in fair colored women. What is not apparent is whether being fair-colored alone is a risk factor for getting ectopic pregnancy independent of the other confounding factors. At $95 \%$ confidence intervals there was a high association between being fair in skin complexion and ectopic pregnancy ( $p$-value $<0.001$ ). 
Opoku et al. Gynecology 2013,

Table 1. Basic demographics.

\begin{tabular}{|c|c|c|c|}
\hline Parameter & Case n (\%) & Control n (\%) & Total n (\%) \\
\hline \multicolumn{4}{|l|}{ Age (years) } \\
\hline$<21$ & $20(18.2)$ & 40 (18.2) & $60(18.2)$ \\
\hline $21-30$ & $63(57.3)$ & $123(55.9)$ & $186(56.4)$ \\
\hline $31-40$ & $26(23.6)$ & $56(25.5)$ & $82(24.8)$ \\
\hline$>40$ & $1(0.9)$ & $1(0.5)$ & $2(0.6)$ \\
\hline \multicolumn{4}{|l|}{ Parity } \\
\hline 0 & 45 (40.9) & $69(31.4)$ & $114(34.5)$ \\
\hline $1-4$ & $63(57.3)$ & $141(64.1)$ & $204(61.8)$ \\
\hline$\geq 5$ & $2(1.8)$ & $10(4.5)$ & $12(3.6)$ \\
\hline \multicolumn{4}{|l|}{ Previous TOP* } \\
\hline Nil & $54(49.1)$ & $116(52.7)$ & $170(51.5)$ \\
\hline 1 & $37(33.6)$ & $63(28.6)$ & $100(30.3)$ \\
\hline 2 & $10(9.1)$ & 35 (15.9) & 45 (13.6) \\
\hline$\geq 3$ & $9(8.2)$ & $6(2.7)$ & $15(4.5)$ \\
\hline \multicolumn{4}{|l|}{ Occupation } \\
\hline Nil & $10(9.1)$ & $14(6.4)$ & $24(7.3)$ \\
\hline Student & $17(15.5)$ & $27(12.3)$ & $44(13.3)$ \\
\hline Apprentice & $9(8.2)$ & $49(22.3)$ & $58(17.6)$ \\
\hline Housewife & $9(8.2)$ & $52(23.6)$ & $61(18.5)$ \\
\hline Employed & $65(59.1)$ & $78(35.5)$ & $143(43.3)$ \\
\hline \multicolumn{4}{|c|}{ Highest level of Education } \\
\hline None & $5(4.5)$ & $14(6.4)$ & $19(5.8)$ \\
\hline Primary/JHS & $56(50.9)$ & $105(47.7)$ & $161(48.8)$ \\
\hline Secondary & $37(33.6)$ & $90(40.9)$ & $127(38.5)$ \\
\hline Tertiary & $12(10.9)$ & $11(5.0)$ & $23(7.0)$ \\
\hline \multicolumn{4}{|l|}{ Marital Status } \\
\hline Single & $44(40.0)$ & $96(43.6)$ & $140(42.4)$ \\
\hline Married & $51(46.4)$ & $102(46.4)$ & $153(46.4)$ \\
\hline Divorced & $3(2.7)$ & $2(0.9)$ & $5(1.5)$ \\
\hline Co-habitation & $12(10.9)$ & $20(9.1)$ & $32(9.7)$ \\
\hline \multicolumn{4}{|c|}{ Lifetime Sexual Partners } \\
\hline 1 & $15(14.4)$ & $23(10.9)$ & $38(12.1)$ \\
\hline 2 & $36(34.6)$ & $70(33.2)$ & $106(33.7)$ \\
\hline 3 & $31(29.8)$ & $76(36.0)$ & $107(34.0)$ \\
\hline 4 & $18(17.3)$ & $41(19.4)$ & $59(18.7)$ \\
\hline$\geq 5$ & $4(3.8)$ & $1(0.5)$ & $5(1.6)$ \\
\hline
\end{tabular}

*Termination of Pregnancy.

Table 2. Relationship between Ectopic pregnancy and clinical and demographic features.

\begin{tabular}{|c|c|c|c|c|c|}
\hline & Total & Case & Control & OR $(95 \% C I)$ & p-value \\
\hline Age (yrs) mean (SD) & $27.0(5.9)$ & $27.1(6.1)$ & $27.0(5.9)$ & $1.02(0.70-1.51)$ & 0.894 \\
\hline Gravidity Gmean* & 1.5 & 1.4 & 1.6 & $0.53(0.36-0.76)$ & 0.001 \\
\hline Parity Gmean* & 0.8 & 0.7 & 0.8 & $0.61(0.43-0.86)$ & 0.005 \\
\hline $\begin{array}{l}\text { Education } \\
\text { (primary or less) n (\%) }\end{array}$ & $180(54.5)$ & $61(55.4)$ & $119(54.1)$ & $1.06(0.66-1.71)$ & 0.809 \\
\hline Single $\mathrm{n}(\%)$ & $185(56.1)$ & $63(57.3)$ & $112(55.4)$ & $1.09(0.65-1.81)$ & 0.730 \\
\hline Facial color Mean(SD) & $7.8(3.0)$ & $7.0(3.3)$ & $8.2(2.8)$ & $1.84(1.37-2.48)$ & $<0.001$ \\
\hline Back color $\operatorname{Mean}(\mathrm{SD})$ & $8.7(2.9)$ & $8.3(3.3)$ & $9.0(2.6)$ & $1.36(1.02-1.81)$ & 0.033 \\
\hline $\begin{array}{l}\text { Color difference } \\
\text { Mean(SD) }\end{array}$ & $0.9(1.6)$ & $1.4(1.9)$ & $0.7(1.3)$ & $1.49(1.18-1.88)$ & 0.001 \\
\hline $\begin{array}{l}\text { Skin Bleaching cream } \\
\text { use } n(\%)\end{array}$ & $79(23.9)$ & $41(37.3)$ & $38(17.3)$ & $2.80(1.64-4.78)$ & $<0.001$ \\
\hline History of PID $\mathrm{n}(\%)$ & $45(13.6)$ & $21(19.1)$ & $24(10.9)$ & $2.16(1.07-4.38)$ & 0.032 \\
\hline History of TOP $\mathrm{n}(\%)$ & $159(48.2)$ & $56(50.9)$ & $103(46.8)$ & $1.18(0.74-1.86)$ & 0.485 \\
\hline $\begin{array}{l}\text { History of Abortion } \\
\mathrm{n}(\%)\end{array}$ & $94(28.8)$ & $22(20.0)$ & $72(42.7)$ & $0.52(0.30-0.90)$ & 0.019 \\
\hline $\begin{array}{l}\text { Previous pelvic surgery } \\
\mathrm{n}(\%)\end{array}$ & $27(8.2)$ & $11(10.0)$ & $16(7.3)$ & $1.43(0.63-3.27)$ & 0.389 \\
\hline $\begin{array}{l}\text { Life time sex partners } \\
\text { Mean(SD) }\end{array}$ & $2.7(1.3)$ & $2.8(1.5)$ & $2.7(1.1)$ & $1.12(0.87-1.43)$ & 0.383 \\
\hline
\end{tabular}

The association with skin complexion was also found irrespective of the colour difference between the face and the back ( $p$-value $<0.001$ ) whether the fairness was natural (fairness on both face and the back) or artificially induced with bleaching of the face (fair on the face but darker on the back). This finding is not surprising if the previous presumption that fair colored women are more sexually attractive to men holds, since it is the face that is initially attractive. There was no association between previous pelvic infection and ectopic pregnancy $(p=0.389)$. This did not support the belief that fair complexioned women are more likely to be promiscuous and thus prone to having reproductive tract infections that could lead to tubal damage. The study also did not show any association between previous pelvic surgery and ectopic pregnancy $(p=0.389)$, neither was there any association with lifetime sexual partners $(p=0.383)$ or previous termination of pregnancy ( $p$-value 0.485 ). These buttress the finding that being fair colored alone is a risk factor for getting ectopic pregnancy.

A major advantage of diagnosis of ectopic pregnancy before rupture is treatment without need to transfuse blood with all its attendant problems. Key to this is the ability to diagnose unruptured ectopic pregnancies. The ability of health professionals to 'think ectopic' is therefore crucial. High level of suspicion is afforded by clinical presentation as well as risk factors that pertain. Thus knowing that being fair in skin color is a risk factor is an added tool in helping diagnose unruptured ectopic pregnancy as well as diagnosing atypical cases such as chronic/ leaking ectopic pregnancy.

\section{Conclusion}

The study has established that being fair in skin complexion in black women is an added risk factor. This risk is found to be irrespective of whether the fairness is natural or has been artificially induced with skin toning or bleaching creams and soaps. This undoubtedly will help practitioners diagnose both ruptured and unruptured ectopic pregnancies.

\section{Competing interests}

The authors declare that they have no competing interests.

\section{Authors' contributions}

BKO designed the study supervised it and wrote the manuscript. SBN did the statistical analysis and also contributed to writing the manuscript.

WZ supervised the collection of data.

\section{Acknowledgement}

We express our sincere thanks to all participants who gratefully accepted to be part of the study as well as the interviewers who gathered data for us.

\section{Publication history}

Received: 21-Mar-2013 Accepted: 25-Mar-2013

Published: 01-Apr-2013

\section{References}

1. Chang J, Elam-Evans LD, Berg CJ, Herndon J, Flowers L, Seed KA and Syverson CJ: Pregnancy-related mortality surveillance--United States, 1991--1999. MMWR Surveill Summ 2003, 52:1-8. I Article I PubMed

2. Ankum WM, Mol BW, Van der Veen F and Bossuyt PM: Risk factors 
Opoku et al. Gynecology 2013,

http://www.hoajonline.com/journals/pdf/2052-6210-1-1.pdf

for ectopic pregnancy: a meta-analysis. Fertil Steril 1996, 65:1093-9. | Article | PubMed

3. Barnhart KT, Sammel MD, Gracia CR, Chittams J, Hummel AC and Shaunik A: Risk factors for ectopic pregnancy in women with symptomatic firsttrimester pregnancies. Fertil Steril 2006, 86:36-43. | Article | PubMed

4. Clayton HB, Schieve LA, Peterson HB, Jamieson DJ, Reynolds MA and Wright VC: Ectopic pregnancy risk with assisted reproductive technology procedures. Obstet Gynecol 2006, 107:595-604. | Article | PubMed

5. ACOG Practice Bulletin No. 94: Medical management of ectopic pregnancy. Obstet Gynecol 2008, 111:1479-85. | Article | PubMed

6. Obed S: Diagnosis of Unruptured Ectopic Pregnancy is Still Uncommon in Ghana. Ghana Med J 2006, 40:3-7. | PubMed Abstract | PubMed Full Text

7. KATH Annual Statistics, 2010.

8. Boufous S, Quartararo M, Mohsin M and Parker J: Trends in the incidence of ectopic pregnancy in New South Wales between 19901998. Aust N Z J Obstet Gynaecol 2001, 41:436-8. | Article | PubMed

\section{Citation:}

Opoku BK, Nguah SB and Azanu W: Ectopic pregnancy: Are fair-colored women at increased risk? Gynecology 2013, 1:1. http://dx.doi.org/10.7243/2052-6210-1-1 